\title{
High Availability of the $\alpha 7$-Nicotinic Acetylcholine Receptor in Brains of Individuals with Mild Cognitive Impairment: A Pilot Study Using ${ }^{18}$ F-ASEM PET
}

\author{
Jennifer M. Coughlin ${ }^{1,2}$, Leah H. Rubin ${ }^{1,3,4}$, Yong Du², Steven P. Rowe ${ }^{2}$, Jeffrey L. Crawford ${ }^{1}$, Hailey B. Rosenthal ${ }^{2}$, \\ Sarah M. Frey ${ }^{2}$, Erica S. Marshall ${ }^{2}$, Laura K. Shinehouse ${ }^{2}$, Allen Chen ${ }^{2}$, Caroline L. Speck ${ }^{1}$, Yuchuan Wang ${ }^{2}$, \\ Wojciech G. Lesniak ${ }^{2}$, Il Minn², Arnold Bakker ${ }^{1}$, Vidyulata Kamath ${ }^{1}$, Gwenn S. Smith ${ }^{1,2}$, Marilyn S. Albert ${ }^{3}$, \\ Babak Behnam Azad ${ }^{2}$, Robert F. Dannals ${ }^{2}$, Andrew Horti ${ }^{2}$, Dean F. Wong ${ }^{1-3,5}$, and Martin G. Pomper ${ }^{1,2}$ \\ ${ }^{1}$ Department of Psychiatry, Johns Hopkins Medical Institutions, Baltimore, Maryland; ${ }^{2}$ Department of Radiology, Johns Hopkins \\ Medical Institutions, Baltimore, Maryland; ${ }^{3}$ Department of Neurology, Johns Hopkins Medical Institutions, Baltimore, Maryland; \\ ${ }^{4}$ Department of Epidemiology, Johns Hopkins Medical Institutions, Baltimore, Maryland; and ${ }^{5}$ Department of Neuroscience, Johns \\ Hopkins Medical Institutions, Baltimore, Maryland
}

\begin{abstract}
Emerging evidence supports a hypothesized role for the a7-nicotinic acetylcholine receptor (a7-nAChR) in the pathophysiology of Alzheimer's disease. ${ }^{18} \mathrm{~F}-\mathrm{ASEM}$ (3-(1,4-diazabicyclo[3.2.2]nonan-4-yl)$6-{ }^{18} \mathrm{~F}$-fluorodibenzo[b,d]thiophene 5,5 -dioxide) is a radioligand for estimating the availability of a7-nAChR in the brain in vivo with PET. Methods: In this cross-sectional study, 14 patients with mild cognitive impairment $(\mathrm{MCl})$, a prodromal stage to dementia, and 17 cognitively intact, elderly controls completed ${ }^{18} \mathrm{~F}$-ASEM PET. For each participant, binding in each region of interest was estimated using Logan graphical analysis with a metabolite-corrected arterial input function. Results: Higher ${ }^{18} \mathrm{~F}$-ASEM binding was observed in $\mathrm{MCl}$ patients than in controls across all regions, supporting higher availability of a7-nAChR in MCl. ${ }^{18} \mathrm{~F}-\mathrm{ASEM}$ binding was not associated with verbal memory in this small $\mathrm{MCl}$ sample. Conclusion: These data support use of ${ }^{18} \mathrm{~F}$-ASEM PET to examine further the relationship between a7-nAChR availability and $\mathrm{MCl}$.
\end{abstract}

Key Words: nAChR; cholinergic; ${ }^{18} \mathrm{~F}-\mathrm{ASEM}$; dementia; PET

J Nucl Med 2020; 61:423-426

DOI: 10.2967/jnumed.119.230979

$\mathbf{T}$

he $\alpha 7$-nicotinic acetylcholine receptor $(\alpha 7-n A C h R)$ may play a mechanistic role in the selective vulnerability of cholinergic cells to neurodegeneration in the earliest phases of Alzheimer's disease (AD) (1). The $\alpha 7$-nAChR binds soluble 42-amino-acid $\beta$-amyloid peptide $(\mathrm{A} \beta 42)$ with picomolar affinity (2), and in $\mathrm{AD}$, the $\mathrm{A} \beta 42-\alpha 7-\mathrm{nAChR}$ interaction may result in dysregulated signal transduction, compromised synaptic plasticity, and a toxic, selective effect on cholinergic cells of the basal forebrain and its projection sites (3). AD mouse models support upregulation of $\alpha 7-n A C h R$ expression in the presence of $A \beta 42$, which promotes further pathologic changes (4). In AD brain tissue, high levels of

Received May 10, 2019; revision accepted Jul. 23, 2019.

For correspondence or reprints contact: Jennifer M. Coughlin, Johns Hopkins Medical Institutions, 600. N. Wolfe St., Meyer 3-181, Baltimore, MD 21287.

E-mail: jcoughl2@jhmi.edu

Published online Aug. 16, 2019.

COPYRIGHT (C 2020 by the Society of Nuclear Medicine and Molecular Imaging. $\alpha 7-n A C h R$ colocalize with intracellular A $\beta 42$ burden (5), and high $\alpha 7-n A C h R$ expression was found on basal forebrain (specifically nucleus basalis) cholinergic neurons (6). Relative to control tissue, a nonsignificant trend toward higher basal forebrain $\alpha 7-n A C h R$ expression was found in cases of mild cognitive impairment (MCI), a prodromal stage to dementia (6).

${ }^{18}$ F-ASEM (3-(1,4-diazabicyclo[3.2.2]nonan-4-yl)-6- ${ }^{18}$ F-fluorodibenzo[b,d]thiophene 5,5-dioxide) is a PET radioligand for estimating the availability of $\alpha 7-\mathrm{nAChR}$ in the brain in vivo and has shown high specific binding in receptor blockade studies in mice (7) and baboons (8). ${ }^{18}$ F-ASEM PET has been used to study the $\alpha 7-n A C h R$ in healthy aging (9) and psychosis (10). In this pilot study, we used ${ }^{18} \mathrm{~F}$-ASEM PET to test for higher in vivo availability of $\alpha 7-n A C h R$ in individuals with MCI than in cognitively intact, healthy controls. Associations between regional ${ }^{18} \mathrm{~F}$-ASEM binding and memory were explored.

\section{MATERIALS AND METHODS}

\section{Human Subjects}

The Johns Hopkins Institutional Review Board approved this prospective study, which was conducted under an Investigational New Drug protocol approved by the U.S. Food and Drug Administration. Participants (nonsmokers over 65 y old) provided written informed consent. Participants completed a clinical assessment, MRI examination, and comprehensive neuropsychological evaluation as previously described (9). Included was the California Verbal Learning Test (11), which is sensitive to detecting memory impairment in MCI. All MCI participants had a global clinical dementia rating (CDR) (12) of 0.5 with a sum-of-boxes score not exceeding 2.5 , and impaired memory on neuropsychological testing (at least 1 SD below normal performance on a memory test). Control participants were in stable health, with a global CDR of 0 (normal). Exclusion criteria included a global CDR of more than 0.5 , a decline in activities of daily living, nicotine use in the past $6 \mathrm{mo}$, a neurological condition other than MCI, substance abuse, current use of medication with potential to affect radiotracer binding (i.e., acetylcholinesterase inhibitors and anticholinergics), or a contraindication to imaging.

The presence of an apolipoprotein $\mathrm{E}(A P O E) \varepsilon 4$ allele is associated with cerebral amyloid burden (13). We classified participants as either an $A P O E \& 4$ carrier (presence of $\geq 1 \varepsilon 4$ allele) or an $A P O E \& 4$ noncarrier, using previously published genotyping methods (9). 


\section{Brain Imaging}

${ }^{18} \mathrm{~F}$-ASEM PET and MRI data were acquired, and PMOD (version 3.7) was used for image processing as previously described (9). MRI volumetric segmentation was conducted with the FreeSurfer software suite (http://surfer.nmr.mgh.harvard.edu/) or MRICloud (www.mricloud.org; for basal forebrain only). The regions of interest included cortical (frontal, parietal, temporal, occipital, cingulate, and cerebellar) and subcortical (hippocampus, thalamus, striatum, and basal forebrain) regions. Total intracranial volume was also estimated using FreeSurfer for comparison of regional atrophy between the 2 groups while accounting for individual variability in head size. Regional volume normalized to intracranial volume is referred to as regional volume ratio.

The kinetics of ${ }^{18} \mathrm{~F}$-ASEM were modeled using Logan graphical analysis (14) with a metabolite-corrected arterial input function obtained from $90 \mathrm{~min}$ of dynamic data, generating a regional ${ }^{18} \mathrm{~F}-\mathrm{ASEM}$ total distribution volume, $\mathrm{V}_{\mathrm{T}}(15)$. To address the effect of atrophy on ${ }^{18} \mathrm{~F}-\mathrm{ASEM}$ binding in the brains of this elderly study population, we report regional $\mathrm{V}_{\mathrm{T}}$ values that were derived from PET data after partial-volume correction (PVC) using the algorithm of Müller-Gärtner et al. (16). $\mathrm{V}_{\mathrm{T}}$ estimates from images without $\mathrm{PVC}$ were secondary binding outcomes.

\section{Statistical Analysis}

Differences in ${ }^{18} \mathrm{~F}-\mathrm{ASEM} \mathrm{V}_{\mathrm{T}}$ between the control and MCI groups were tested using a linear mixed-effects regression model to accommodate within-subject assessment of brain regions that are associated to different degrees. Primary predictors included group, an index variable for brain region, and the 2-way interaction. Significance was set at a $P$ value of less than 0.05 for this single mixed-effects regression model analysis. Pearson partial correlations were conducted to explore relationships within the MCI group between ${ }^{18} \mathrm{~F}$-ASEM binding and performance on California Verbal Learning Test short- and long-delay free recall. Age was included in all models as a covariate because age may affect ${ }^{18} \mathrm{~F}$-ASEM binding (9). When group differences emerged, subsequent models were run with the adjustment for not only age but also for race, sex, and $A P O E \& 4$ carrier status. Because there were 2 primary memory outcomes, the threshold for significance was set at a $P$ value of less than $0.025(=0.05 / 2)$ for examining these correlations.

\section{RESULTS}

\section{Participants}

Clinical characteristics, $A P O E \& 4$ carrier status, and relevant imaging parameters were similar between the control $(n=17)$ and MCI $(n=14)$ groups (Table 1$)$. After age adjustment, patients with MCI had higher scores than controls on the sum-of-boxes CDR $(P=0.001)$ and lower scores on the 2 California Verbal Learning Test outcomes (each $P<0.025$ ).

\section{Imaging}

In age-adjusted analyses, there was a near-significant group $\times$ region interaction $\left(\mathrm{F}_{9,28}=2.21, P=0.05\right)$ indicating that there were group differences in some but not all MRI-based segmentation regional volumes. Specifically, the MCI group had smaller hippocampal $(P=0.001)$ and thalamic $(P=0.04)$ volumes than controls (Supplemental Table 1; supplemental materials are available at http://jnm.snmjournals.org). The same pattern of differences was seen in regional volume ratios after age adjustment.

The metabolism of ${ }^{18} \mathrm{~F}$-ASEM over the scan duration did not differ between groups at any time point. At 10, 45, and $90 \mathrm{~min}$ after injection, mean parent fractions were $69 \% \pm 7 \%, 28 \% \pm$ $9 \%$, and $14 \% \pm 5 \%$, respectively, among the MCI group and $68 \% \pm 6 \%, 29 \% \pm 8 \%$, and $15 \% \pm 4 \%$, respectively, among the controls. In age-adjusted analyses using images after PVC, the MCI group had a higher ${ }^{18} \mathrm{~F}-\mathrm{ASEM} \mathrm{V}_{\mathrm{T}}$ (estimated mean, 31.51; SE, 1.14) than did controls (estimated $\mathrm{M}, 27.23$; SE, 1.04; $\mathrm{F}_{1,28}=7.02$, $P=0.01$; Cohen's d $=0.999 ; 95 \%$ confidence interval, $0.25-$ $1.75)$, with the pattern of group differences similar across all regions $\left(\mathrm{F}_{9,28}=1.37, P=0.25\right.$; Fig. 1; Supplemental Table 2). Rerunning the model after further adjusting for race, sex, and $A P O E \varepsilon 4$ carrier

TABLE 1

Clinical Characteristics and PET Parameters Among Healthy Controls and Patients with MCI

\begin{tabular}{|c|c|c|c|}
\hline Characteristic & Control $(n=17)$ & $\mathrm{MCl}(n=14)$ & $P$ \\
\hline Age $(y)$ & $76.4 \pm 6.2$ & $80.5 \pm 5.5$ & 0.06 \\
\hline Sex (male) & $9(53 \%)$ & $7(50 \%)$ & 0.88 \\
\hline Race (African American; Caucasian; Asian) & 4 (24\%); 12 (71\%); 1 (6\%) & 7 (50\%); 7 (50\%); 0 (0\%) & 0.24 \\
\hline Education (y) & $17.1 \pm 3.3$ & $15.7 \pm 4.3$ & 0.35 \\
\hline Body mass index & $26.5 \pm 3.0$ & $26.7 \pm 3.2$ & 0.92 \\
\hline Genetic vulnerability, $A P O E$ ع4 carrier (yes) & $3(18 \%)$ & $5(36 \%)$ & 0.28 \\
\hline \multicolumn{4}{|l|}{ Cognitive performance } \\
\hline Sum-of-boxes CDR & $0.0 \pm 0.1$ & $1.1 \pm 0.7$ & $<0.001$ \\
\hline CVLT short-delay free recall & $11.2 \pm 2.9$ & $7.9 \pm 4.0$ & 0.02 \\
\hline CVLT long-delay free recall & $11.8 \pm 2.7$ & $7.6 \pm 5.0$ & 0.02 \\
\hline \multicolumn{4}{|l|}{ PET parameters } \\
\hline Molar activity (GBq/ $\mu \mathrm{mol})$ & $3,878.1 \pm 2,614.6$ & $3,327.1 \pm 2,133.8$ & 0.52 \\
\hline Injected dose of radioactivity (MBq) & $516.2 \pm 22.2$ & $517.2 \pm 17.7$ & 0.89 \\
\hline Injected mass $(\mu \mathrm{g})$ & $0.08 \pm 0.06$ & $0.11 \pm 0.12$ & 0.43 \\
\hline
\end{tabular}

CVLT $=$ California Verbal Learning Test.

$P$ values are from comparison using Student $t$ test or $\chi^{2}$ test as appropriate except for comparison of cognitive performance, which was assessed using analysis of covariance with age as covariate. Qualitative data are expressed as numbers followed by percentages in parentheses; continuous data are expressed as mean \pm SD. 
status resulted in the same pattern of higher ${ }^{18} \mathrm{~F}-\mathrm{ASEM} \mathrm{V}_{\mathrm{T}}$ in $\mathrm{MCI}$ patients than in controls $\left(\mathrm{F}_{1,24}=11.03, P=0.003\right)$.

Among secondary ${ }^{18} \mathrm{~F}$-ASEM binding outcomes (Supplemental Table 3), a similar but nonsignificant binding pattern was observed using $\mathrm{V}_{\mathrm{T}}$ derived from data without $\mathrm{PVC}$ and age adjustment $\left(\mathrm{F}_{1,28}=3.81, P=0.06\right)$. After further adjusting for race, sex, and $A P O E \& 4$ carrier status, the group difference was significant $\left(\mathrm{F}_{1,24}=9.06, P=0.006\right)$.

Among patients with MCI, there were no associations between regional ${ }^{18} \mathrm{~F}-A S E M V_{\mathrm{T}}$ and California Verbal Learning Test performance (Supplemental Table 4).

\section{DISCUSSION}

Our ${ }^{18} \mathrm{~F}$-ASEM PET data are consistent with higher availability of the $\alpha 7-\mathrm{nAChR}$ in MCI patients than in healthy controls across multiple brain regions. These pilot results align with postmortem studies reporting higher $\alpha 7$-nAChR levels in early stages of $\mathrm{AD}(6)$, as well as with animal models of $\mathrm{AD}(4,17)$. If validated as a mechanistically linked biomarker, high $\alpha 7-\mathrm{nAChR}$ availability may prove useful for earlier detection and therapeutic intervention in $\operatorname{AD}(18,19)$.

We acknowledge limitations in this study. First, $V_{\mathrm{T}}$ reflects specifically bound and nondisplaceable (nonspecifically bound or free) radiotracer. Human ${ }^{18} \mathrm{~F}$-ASEM PET data do not support a brain region without $\alpha 7-n A C h R$ that could be used as reference tissue for reporting the outcome of specifically bound (relative to nondisplaceable) ${ }^{18} \mathrm{~F}$-ASEM. This widespread $\alpha 7$-nAChR distribution in human brain is similar to that reported in rhesus monkeys and differs from rodent brain (20). $\mathrm{V}_{\mathrm{T}}$ was derived from images after PVC that adjusts the PET signal for regional brain atrophy seen in neurodegeneration. Consistent with published MCI work and supporting use of PVC, we saw smaller hippocampal and thalamic

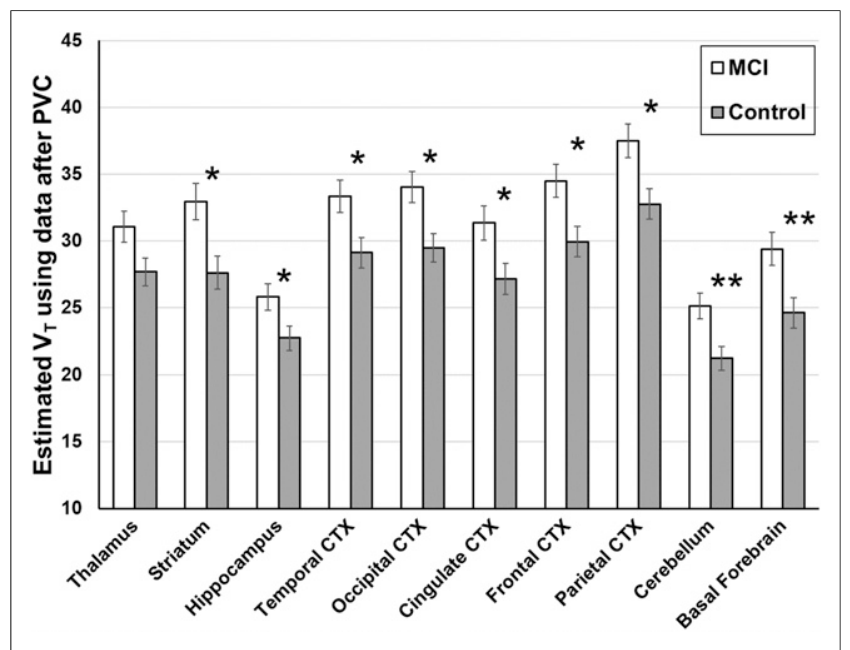

FIGURE 1. Higher ${ }^{18} \mathrm{~F}$-ASEM regional $\mathrm{V}_{\mathrm{T}}$ was found in 14 participants with $\mathrm{MCl}$ than in 17 cognitively intact healthy control participants, after accounting for age. Box plot diagram of ${ }^{18} \mathrm{~F}-\mathrm{ASEM} \mathrm{V}_{\mathrm{T}}$ was derived from images after PVC across 10 regions of interest. A linear mixed-effects regression model adjusting for age and brain region demonstrated higher $\mathrm{V}_{\mathrm{T}}$ in $\mathrm{MCl}$ patients than in controls. In secondary analyses, a regional difference for each region except thalamus was found between $\mathrm{MCl}$ patients and controls using individual linear regression models fit for region of interest and controlling for age $\left({ }^{*} P<0.05 ;{ }^{*} P<0.01\right)$. These differences in individual regions did not remain significant after Bonferroni adjustment for 10 regions tested, which required $P<0.005$. $V_{T}$ is in units of $\mathrm{mL} \mathrm{cm}^{-3}$. CTX $=$ cortex. volumes in MCI patients than in controls after age adjustment. However, a risk of using PVC is false elevation of regional $\mathrm{V}_{\mathrm{T}}$ estimates due to overcompensation by the method. In this study, model analysis using $\mathrm{V}_{\mathrm{T}}$ from images without $\mathrm{PVC}$ produced a similar, albeit nonsignificant, pattern of higher binding in MCI patients than in controls after age adjustment, which achieved significance after further adjustment for other factors (sex, race, and $A P O E \& 4$ carrier status). Second, whereas these findings suggest a role for the $\alpha 7-n A C h R$ in MCI, the cross-sectional study design and lack of amyloid markers in our pilot population limit the ability to assess causality or specificity to AD-mediated MCI (as opposed to MCI from non-AD pathology). The lack of association between ${ }^{18} \mathrm{~F}$-ASEM $\mathrm{V}_{\mathrm{T}}$ and verbal memory impairment in this study may be due to possible inclusion of MCI participants with non-AD disease. Furthermore, here we focused on brain tissue, but the $\alpha 7 \mathrm{nAChR}$ in cerebral vasculature may promote cerebral amyloid angiopathy (21), which is common in $\mathrm{AD}$ and linked to impaired memory. Complementary animal studies that manipulate $\alpha 7-n A C h R$ availability or activity should be pursued to evaluate causal, mechanistic relationships between the $\alpha 7$ $\mathrm{nAChR}$ and AD pathophysiology. Future studies designed to test the relationships between ${ }^{18} \mathrm{~F}$-ASEM binding and neuropsychological performance in larger clinical samples are needed.

\section{CONCLUSION}

Our ${ }^{18}$ F-ASEM PET data support a higher availability of the $\alpha 7-n A C h R$ across several brain regions in individuals with MCI than in healthy individuals.

\section{DISCLOSURE}

This work was supported by the Henry N. Wagner, Jr., Endowment, a Johns Hopkins Doris Duke Foundation Early Clinician Investigator Award, and the Johns Hopkins Alzheimer Disease Research Center (P50 AG005146). No other potential conflict of interest relevant to this article was reported.

\section{ACKNOWLEDGMENT}

We thank the Johns Hopkins PET Center for providing the ${ }^{18} \mathrm{~F}-$ ASEM.

\section{KEY POINTS}

QUESTION: Is the availability of the a7-nicotinic acetylcholine receptor ( $\mathrm{a} 7-\mathrm{nAChR})$ altered in brains of individuals with mild cognitive impairment $(\mathrm{MCl})$ ?

PERTINENT FINDINGS: In this cross-sectional study using PET, regional binding of $18 \mathrm{~F}$-ASEM that targets the a7-nAChR was compared between patients $\mathrm{MCl}$ and cognitively intact, elderly controls. Higher ${ }^{18} \mathrm{~F}-\mathrm{ASEM}$ binding was observed in $\mathrm{MCl}$ compared with controls across all brain regions.

IMPLICATIONS FOR PATIENT CARE: ${ }^{18}$ F-ASEM is a promising radiotracer to test further the relationship between the availability of the a7-nAChR and $\mathrm{MCl}$ in vivo with PET.

\section{REFERENCES}

1. Hernandez CM, Dineley KT. Alpha7 nicotinic acetylcholine receptors in Alzheimer's disease: neuroprotective, neurotrophic or both? Curr Drug Targets. 2012;13:613-622. 
2. Wang HY, Lee DH, D'Andrea MR, Peterson PA, Shank RP, Reitz AB. Betaamyloid(1-42) binds to alpha7 nicotinic acetylcholine receptor with high affinity: implications for Alzheimer's disease pathology. J Biol Chem. 2000;275:5626-5632.

3. Parri HR, Hernandez CM, Dineley KT. Research update: alpha7 nicotinic acetylcholine receptor mechanisms in Alzheimer's disease. Biochem Pharmacol. 2011;82: 931-942.

4. Dineley KT, Xia X, Bui D, Sweatt JD, Zheng H. Accelerated plaque accumulation, associative learning deficits, and up-regulation of alpha 7 nicotinic receptor protein in transgenic mice co-expressing mutant human presenilin 1 and amyloid precursor proteins. J Biol Chem. 2002;277:22768-22780.

5. Nagele RG, D'Andrea MR, Anderson WJ, Wang HY. Intracellular accumulation of beta-amyloid(1-42) in neurons is facilitated by the alpha 7 nicotinic acetylcholine receptor in Alzheimer's disease. Neuroscience. 2002;110:199-211.

6. Counts SE, He B, Che S, et al. Alpha7 nicotinic receptor up-regulation in cholinergic basal forebrain neurons in Alzheimer disease. Arch Neurol. 2007;64: 1771-1776.

7. Wong DF, Kuwabara H, Pomper M, et al. Human brain imaging of alpha7 nAChR with ${ }^{18}$ F-ASEM: a new PET radiotracer for neuropsychiatry and determination of drug occupancy. Mol Imaging Biol. 2014;16:730-738.

8. Horti AG, Gao Y, Kuwabara H, et al. ${ }^{18} \mathrm{~F}-\mathrm{ASEM}$, a radiolabeled antagonist for imaging the alpha7-nicotinic acetylcholine receptor with PET. J Nucl Med. 2014;55: $672-677$.

9. Coughlin JM, Du Y, Rosenthal HB, et al. The distribution of the alpha7 nicotinic acetylcholine receptor in healthy aging: an in vivo positron emission tomography study with ${ }^{18}$ F-ASEM. Neuroimage. 2018;165:118-124.

10. Coughlin J, Du Y, Crawford JL, et al. The availability of the alpha7 nicotinic acetylcholine receptor in recent-onset psychosis: a study using ${ }^{18} \mathrm{~F}$-ASEM PET. J Nucl Med. December 20, 2018 [Epub ahead of print].

11. Delis DC, Kramer JH, Kaplan E, Ober BA. CVLT: California Verbal Learning Test-Adult Version: Manual. San Antonio, TX: Psychological Corporation; 1987.

12. Morris JC. The Clinical Dementia Rating (CDR): current version and scoring rules. Neurology. 1993;43:2412-2414.
13. Risacher SL, Kim S, Shen L, et al. The role of apolipoprotein E (APOE) genotype in early mild cognitive impairment (E-MCI). Front Aging Neurosci. 2013;5:11.

14. Logan J, Fowler JS, Volkow ND, et al. Graphical analysis of reversible radioligand binding from time-activity measurements applied to $\mathrm{N}-{ }^{11} \mathrm{C}$-methyl]-(-)-cocaine PET studies in human subjects. J Cereb Blood Flow Metab. 1990;10:740747.

15. Innis RB, Cunningham VJ, Delforge J, et al. Consensus nomenclature for in vivo imaging of reversibly binding radioligands. J Cereb Blood Flow Metab. 2007;27: 1533-1539.

16. Müller-Gärtner HW, Links JM, Prince JL, et al. Measurement of radiotracer concentration in brain gray matter using positron emission tomography: MRIbased correction for partial volume effects. J Cereb Blood Flow Metab. 1992; 12:571-583.

17. Jones IW, Westmacott A, Chan E, et al. Alpha7 nicotinic acetylcholine receptor expression in Alzheimer's disease: receptor densities in brain regions of the APP(SWE) mouse model and in human peripheral blood lymphocytes. $J \mathrm{Mol}$ Neurosci. 2006;30:83-84.

18. Takata K, Amamiya T, Mizoguchi H, et al. Alpha7 nicotinic acetylcholine receptor-specific agonist DMXBA (GTS-21) attenuates Abeta accumulation through suppression of neuronal gamma-secretase activity and promotion of microglial amyloid-beta phagocytosis and ameliorates cognitive impairment in a mouse model of Alzheimer's disease. Neurobiol Aging. 2018;62:197-209.

19. Uteshev VV. The therapeutic promise of positive allosteric modulation of nicotinic receptors. Eur J Pharmacol. 2014;727:181-185.

20. Han ZY, Zoli M, Cardona A, Bourgeois JP, Changeux JP, Le Novere N. Localization of ${ }^{3} \mathrm{H}$-nicotine, ${ }^{3} \mathrm{H}$-cytisine, ${ }^{3} \mathrm{H}$-epibatidine, and ${ }^{125} \mathrm{I}$-alpha-bungarotoxin binding sites in the brain of Macaca mulatta. J Comp Neurol. 2003;461:49-60.

21. Clifford PM, Siu G, Kosciuk M, et al. Alpha7 nicotinic acetylcholine receptor expression by vascular smooth muscle cells facilitates the deposition of Abeta peptides and promotes cerebrovascular amyloid angiopathy. Brain Res. 2008;1234: $158-171$. 